\title{
Pênfigo Foliáceo em cães: levantamento retrospectivo de casos atendidos no período de novembro de 1986 a julho de 2000 e de resposta aos protocolos de terapia empregados no Hospital Veterinário da USP
}

\author{
Pemphigus foliaceous in dogs: retrospective survey of cases, during the \\ period of November 1998 to July 2000, and evaluation of clinical \\ management in the Veterinary Teaching Hospital of University of São Paulo
}

\author{
Ana Cláudia Balda, ${ }^{*}$ Mary Otsuka, ${ }^{* *}$ Nilceo Schwery Michalany, ${ }^{* \star *}$ Carlos Eduardo Larsson ${ }^{\star \star \star \star *}$
}

\begin{abstract}
Resumo
Entre novembro de 1986 e julho de 2000, foram atendidos, no Serviço de Dermatologia do Hospital Veterinário (HOVET) da Faculdade de Medicina Veterinária e Zootecnia da Universidade de São Paulo (FMVZUSP), 30 animais acometidos por Pênfigo Foliáceo (PF). Através de levantamento retrospectivo, os animais foram caracterizados quanto ao sexo, definição racial e raça, idade, tipo e topografia das lesões e resposta a tratamento orto (prednisona) e heterodoxo (prednisona em associação à azatioprina)
\end{abstract}

Palavras-chave: pênfigo foliáceo, terapia, cães.

\begin{abstract}
Between the period of November 1986 and July 2000, were attended in the Serviço de Dermatologia do Hospital Veterinário (HOVET) da Faculdade de Medicina Veterinária e Zootecnia da Universidade de São Paulo (FMVZUSP), 30 dogs with Pemphigus Foliaceus. Through a retrospective survey, the animals were caracterized by species, sex, breed, age, morphologic characteristics and site of the lesions, response to the therapy only with prednisone and with the association of prednisone and azathioprine.
\end{abstract}

Keywords: pemphigus foliaceus, therapy, dogs.

\section{Introdução}

O Pênfigo Foliáceo (PF) ou, classicamente, Doença de Cazenave, inclui-se dentre as doenças do complexo pênfigo, que pertencem ao grupo das dermatoses auto-imunes. $O$ termo pênfigo foi utilizado inicialmente em medicina humana para designar doenças vésico-bolhosas, já que a palavra deriva do grego (pemphix, pomphos, pompholix) com significado de bolha (Ihrke, 1985). Atualmente, refere-se a um grupo de doenças com comprometimento cutâneo e algumas vezes de mucosas, que têm como característica comum a presença de vesículas ou bolhas intra-epidérmicas (Sampaio e Rivitti, 1998). Apesar de haver similaridades relativamente ao quadro mórbido humano, sabe-se que, nos animais, apenas a variante vulgar do pênfigo acarreta formação de verdadeiras vesículas intra-epidérmicas. Aliás, a fase vésico- bolhosa propriamente dita raramente é observada nas outras formas de pênfigo (Scott et al., 2001). Destarte, freqüentemente, evidenciam-se pústulas frágeis, que se rompem facilmente devido à menor espessura da epiderme do cão, quando comparada àquela do homem. Como conseqüência, são observadas, com maior freqüência, lesões residuais crostosas em decorrência da precoce ruptura das pústulas. O primeiro caso de PF descrito em cães data de 1977 (Halliwell e Goldshmidt apud Scott e Lewis, 1981). Desde então, muito se tem estudado sobre as doenças do complexo pênfigo, tanto no homem como nos animais.

Nas doenças auto-imunes, os anticorpos ou linfócitos ativados são dirigidos contra células do próprio organismo. Apesar da fisiopatologia do desenvolvimento lesional nessas enfermidades auto-imunes estar bem determinada, não se sabe,

\footnotetext{
* Médica-veterinária. Ex-pós-graduanda do Departamento de Clínica Médica da Faculdade de Medicina Veterinária e Zootecnia da Universidade de São Paulo (FMVZ/USP). E-mail: acbalda@aol.com

** Médica-veterinária Serviço de Dermatologia do Hospital Veterinário (HOVET) da FMVZ/USP.

*** Professor Associado do Departamento de Anatomia Patológica da Escola Paulista de Medicina da Universidade Federal de São Paulo (EPM/ UNIFESP).

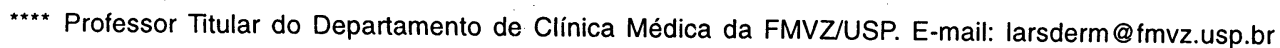


ainda, o que estimularia tais anormalidades no sistema imune (Werner, 1999). A predisposição genética parece ter um papel importante no desenvolvimento da auto-imunidade, mas múltiplos fatores devem estar envolvidos nessa alteração funcional. Dentre os supostos eliciadores do PF incluem-se: drogas, infecções virais, imunógenos e, mesmo, condições inflamatórias de decurso crônico.

O diagnóstico é estabelecido através de dados anamnésticos, exame físico, dermatológico, através da caracterização lesional (quanto ao tipo e à localização das lesões) e de exames complementares. Dentre estes exames, o histopatológico de fragmento de pele biopsiada é aquele a destacar para a consecução do diagnóstico. A lesão de eleição, em termos de colheita, é a pústula, pois é em seu interior que se localizam as células acantolíticas (células de Tzanck), que são células da camada espinhosa que perderam suas pontes de desmossomos e se encontram "soltas" na epiderme. Histologicamente, o pênfigo se caracteriza por acantólise, intragranular ou subcorneal, que resulta na formação de verdadeiras fendas retratadas pelo surgimento de pústulas.

O tratamento ortodoxo eletivo para as enfermidades tegumentares auto-imunes é a glicocorticoideterapia sistêmica empregada em doses imunossupressoras. Porém, tem-se observado, por vezes, a não remissão do quadro quando do uso isolado dos glicocorticóides. Por isso, em muitos casos, se faz necessário o uso de protocolo heterodoxo através da utilização de glicocorticóides associados a citostáticos, para que haja potencialização dos seus efeitos antiinflamatórios e imunossupressores. Através dessa combinação terapêutica, as doses usuais de cada uma das drogas normalmente empregadas podem ser reduzidas, com isto, minimizando seus eventuais efeitos colaterais (Beale, 1988).

Scott et al., 2001, afirmaram que os glicocorticóides são ineficazes em pelo menos $50 \%$ dos casos de PF. Ihrke et al. (1985) relataram que apenas $39 \%$ dos cães respondem ao uso dos corticosteróides. Já White (2000) considerou que tão-somente $20 \%$ dos cães e gatos com doenças auto-imunes são bem controlados com administração de glicocorticóides. Na bibliografia brasileira há apenas um relato de cão penfigoso não responsivo à corticoterapia, sendo que a terapia alternativa nele utilizada foi a associação tetraciclina e nicotinamida (Nascimento et al., 2000).

Naqueles casos refratários à terapia ortodoxa ou quando se anseia reduzir a dose de esteróides, preconiza-se o emprego da azatioprina, um análogo da purina que originalmente foi desenvolvida como agente antineoplásico. A azatioprina isoladamente, nem sempre é efetiva na indução da remissão clínica de doenças imunomediadas, por isso, precisa ser utilizada sempre em associação com corticosteróides. A dosagem comumente utilizada na terapia de indução em cães é a de $2 \mathrm{mg} / \mathrm{kg}$, por dia durante quatro a seis semanas. $O$ intervalo posológico pode ser posteriormente aumentado, ministrando-se a droga a cada 48 horas. Esse fármaco não parece atingir plena efetividade antes de pelo menos três semanas de administração.

Em função destas considerações e pela exigüidade de trabalhos brasileiros, caracterizando a Doença de Cazenave, em espécimes domésticos objetiva-se caracterizar os ani- mais da espécie canina, atendidos no Serviço de Dermatologia do Hospital Veterinário da Faculdade de Medicina Veterinária e Zootecnia da Universidade de São Paulo (FMVZ/USP), com diagnóstico estabelecido de PF, quanto ao sexo, definição racial e raça, idade, tipos e topografia de lesões e, ainda, o de analisar a resposta dos pacientes caninos à terapia à base de prednisona e/ou azatioprina.

\section{Material e métodos}

A amostragem, constituída de 30 cães penfigosos, foi obtida através de levantamento retrospectivo dos casos atendidos no Serviço de Dermatologia do HOVET da FMVZ/USP, em período de 129 meses (novembro de 1986 a julho de 2000), com o diagnóstico firmado de PF. Uma vez coligidos os dados anamnésticos e procedidos os exames físico e dermatológico, caracterizando, através deste, os tipos de lesões cutâneas elementares e a topografia destas, estabelecida a hipótese diagnóstica, realizava-se a colheita; através de punção do conteúdo das formações vésico-bolhopustulares existentes e submetiam-se os animais, previamente sedados, à biópsia de pele lesada, com auxílio do punch de Key" O material obtido através da punção era submetido a exame citológico pelo método de Tzanck (Sampaio e Rivitti, 1998). Já aquele provindo das biópsias era, após fixação em formalina a 10\%, submetido às técnicas histológicas usuais em laboratório privado de dermatopatologia.

Quando necessário, os animais foram submetidos a outros exames subsidiários para que fossem descartadas outras hipóteses diagnósticas eventualmente condizentes com 0 quadro dermatopático.

Estabelecido o diagnóstico, iniciava-se a clássica terapia, "per os", com glicocorticóides, utilizando-se da prednisona, ${ }^{1}$ em dose imunossupressora ( $2 \mathrm{mg} / \mathrm{kg})$, até a obtenção de melhora clínica evidente (duas a três semanas). Iniciava-se, então, a diminuição da dose do corticosteróide até se obter a menor dosagem possível de controle do quadro sintômato-lesional. Nos casos em que a corticoterapia oral não surtia o efeito ansiado, recorria-se à associação da azatioprina, "per os", na dosagem de $2 \mathrm{mg} / \mathrm{kg}$, diariamente.

\section{Resultados}

Dos 30 cães penfigosos, $13(43,3 \%)$ animais eram machos e os $17(56,7 \%)$ remanescentes eram fêmeas (Gráfico 1$)$.

Quanto à definição racial e raça, constatou-se que apenas 12 (40\%) animais não eram de raça definida. Daqueles $18(60 \%)$, com plena definição racial, cinco cães eram da raça Cocker Spaniel $(27,7 \%)$ e três animais pertenciam à raça Pastor Alemão $(16,6 \%)$. Os demais $10(55,7 \%)$ cães eram de outras dez distintas raças (Tabela 1 ).

Com relação à idade, quando do estabelecimento do quadro, observou-se que $20(66,5 \%)$ dos cães acometidos pelo PF tinham entre quatro e nove anos, seis $(20 \%)$ entre um e três anos, três (10\%) situavam-se na faixa etária acima de nove anos e, finalmente, um (3,5\%) cão tinha menos de um ano de

\footnotetext{
1 Meticorten® - Schering Plough - comprimidos de 5 e $20 \mathrm{mg}$

2 Imuran® - Glaxo Wellcome - comprimidos de 50mg
} 
idade.

As lesões mais comumente observadas nos animais com PF foram: crostas hemo-melicéricas $(100 \%)$, pústulas $(53,3 \%)$, alopecia $(40,0 \%)$ e hiperqueratose palmo-plantar $(33,3 \%)$. As demais lesões evidenciadas incluíam: pápulas, escamas, colaretes epidérmicos e discromia (eritema e hiperpigmentação) em diferentes percentis (Tabela 2). As lesões iniciais acometiam (Tabela 3) mais freqüentemente os pavilhões auriculares $(73,3 \%)$, a região ventral $(70 \%)$, a ponte nasal e o dorso dos animais (53,3\%).

Em 28 (93\%) dos casos houve a generalização do quadro em período de um a seis meses. O prurido foi caracterizado quantitativamente como: ausente (escala de 0 a 2), discreto ( 3 a 5), moderado (6 a 8) e intenso (9 e 10). Assim, dez (33,3\%) animais apresentavam ausência de prurido, dois $(6,7 \%)$ manifestavam prurido discreto, três $(10 \%)$ prurido moderado e $15(50,0 \%)$ apresentavam prurido intenso.

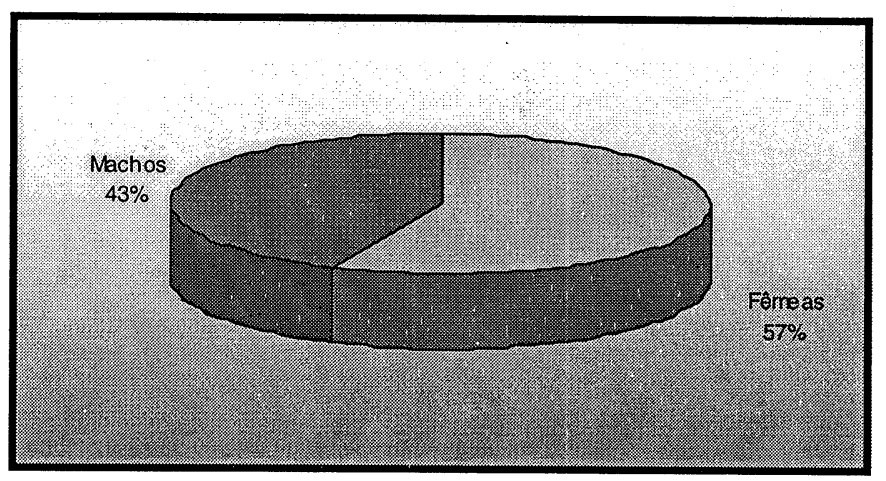

Gráfico 1: Ocorrência de Pênfigo foliáceo em cães segundo o sexo. Serviço de Dermatologia HOVET/FMVZ-USP (novembro de 1986 a julho de 2000)
Tabela 2: Caracterização lesional dos 30 cães com diagnóstico de Pênfigo Foliáceo. Serviço de Dermatologia HOVET/ FMVZ-USP (novembro de 1986 a julho de 2000)

\begin{tabular}{ccc}
\hline Lesões elementares & $\mathbf{n}^{\circ}$ de animais & $\%$ \\
\hline Crostas hemo-melicéricas & 30 & 100,0 \\
Pústulas & 16 & 53,3 \\
Alopecia & 12 & 40,0 \\
Eritema & 10 & 33,3 \\
Hiperqueratose & 10 & 33,3 \\
Pápulas & 8 & 26,6 \\
Escamas & 8 & 26,6 \\
Colaretes epidérmicos & 6 & 20,0 \\
Hiperpigmentacão & 2 & 6,6 \\
\hline
\end{tabular}

* melicéricas (27-90\%) e hemáticas (3-10\%)

Tabela 3: Distribuição topográfica das lesões cutâneas dos 30 cães com diagnóstico de Pênfigo Foliáceo. Serviço de Dermatologia HOVET/FMVZ-USP (novembro de 1986 a julho de 2000)

\begin{tabular}{ccc}
\hline Localização & $\mathbf{n}^{\circ}$ de animais & $\%$ \\
\hline Pavilhões auriculares & 22 & 73,3 \\
Região ventral & 21 & 70,0 \\
Ponte nasal & 16 & 53,3 \\
Região dorsal & 16 & 53,3 \\
Membros & 11 & 36,6 \\
Coxins palmo-plantares & 10 & 33,3 \\
Região cervical & 9 & 30,0 \\
Região periocular & 5 & 16,6 \\
Bolsa escrotal & 3 & 10,0 \\
Região axilar & 1 & 3,3 \\
Região coccígea & 1 & 3,3 \\
\hline
\end{tabular}

Tabela 1: Ocorrência de pênfigo foliáceo em cães segundo definição racial e raça. Serviço de Dermatologia HOVET/FMVZ-USP (novembro de 1986 a julho de 2000)

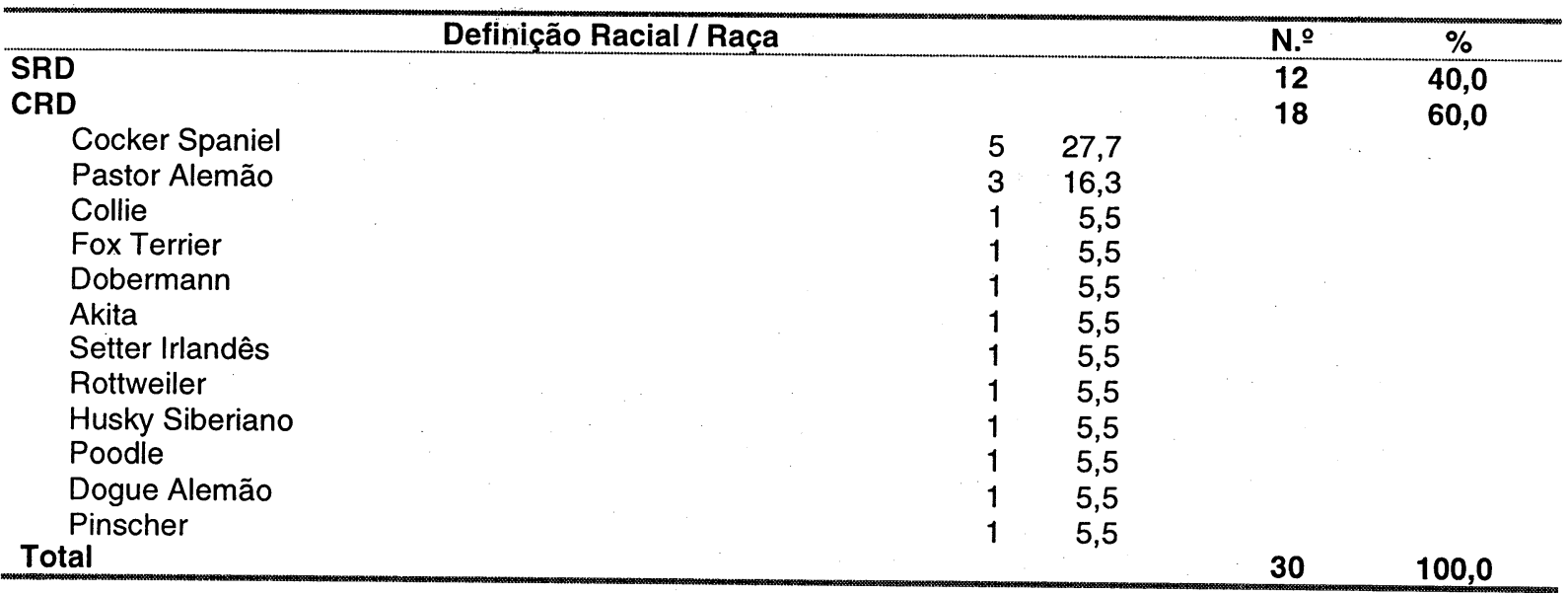


Dos 30 cães atendidos, com PF no Serviço, cinco $(16,6 \%)$ animais não manifestaram a resposta esperada com o uso do corticosteróide. Nesse grupo de animais foram observados dois tipos de resposta: quatro (80\%) animais não obtiveram melhora alguma das lesões cutâneas com o uso isolado do glicocorticóide em nenhum momento do tratamento, nem mesmo com o aumento da dose. Um (20\%) animal apresentou resposta satisfatória durante um mês, obtendo-se, inclusive, remissão total do quadro para, a seguir haver recidiva das lesões cutâneas, que assim persistiram, mesmo com o aumento da dose da prednisona. Em face da má resposta evidenciada à corticoterapia, associou-se, nesses cinco $(16,6 \%)$ casos, a azatioprina.

Daqueles quatro animais nos quais não se observou melhora clínica no transcurso da administração isolada da prednisona, após a introdução da azatioprina $(2 \mathrm{mg} / \mathrm{kg}$, diários, VO), juntamente com o corticosteróide, houve remissão total das lesões, em 12 semanas, sendo esta evidenciada, no primeiro animal, em nove semanas no segundo e em 13 semanas no terceiro dos animais. O quarto animal, ainda sob seguimento, não apresentou a remissão total das lesões, porém o proprietário refere melhora de $80 \%$ com relação ao aspecto lesional, decorridas oito semanas da introdução da azatioprina. A totalidade dos proprietários avaliou a melhora clínica de seus animais como da ordem de, pelo menos, 70 a $80 \%$, já na sexta semana de terapia associada. No outro animal, que havia apresentado melhora clínica no início do tratamento e posteriormente manifestado recidiva do quadro, adotou-se o mesmo esquema terapêutico. Obteve-se melhora clínica, da ordem de $80 \%$, segundo avaliação subjetiva do proprietário, quatro semanas após a introdução da azatioprina. Oito semanas após, retornou ao HOVET, completamente livre de lesões cutâneas.

Em nenhum dos cinco cães submetidos à terapia associada (corticosteróide e azatioprina) se observou qualquer efeito colateral, sistêmico ou tegumentar, indesejável.

\section{Discussão}

Relativamente ao sexo, não pareceu haver predisposição sexual, já que os percentis de acometimento eram muito próximos, quais sejam: $43,3 \%$ dos animais eram machos e $56,7 \%$ fêmeas, dados comparáveis àqueles dispostos na literatura especializada (Ihrke et al., 1985; Bensignor et al., 1998).

Observou-se, ainda, que a maioria dos cães (18 - 60,0\%) com PF tinham plena definição racial. Destes, as raças mais freqüentemente acometidas nessa casuística foram: Cocker Spaniel $(5-27,7 \%)$ e Pastor Alemão (3-16,6\%). A maioria dos autores (Ihrke et al., 1985; Bensignor et al., 1998; SCOTT et al., 2001) referem que existe evidente predisposição dos animais com raça definida ao PF, porém, de acordo com tais autores, as raças mais predispostas seriam: Akita e ChowChow.

A maioria dos animais $(20-66,5 \%)$ situava-se na faixa etária dos 4 a 9 anos de idade, quando do início do quadro. A idade variou, quando das primeiras manifestações mórbidas, entre 11 meses e 12 anos, sendo que a média de idade foi de 5,1 anos, dados estes comparáveis àqueles dispostos na bibliografia (IHRKE et al., 1985). Estes últimos autores observaram uma variação, quanto à faixa etária, de menos de um a 12 anos, com média de 4,2 anos.
Com relação às lesões e à sua topografia, constatou-se que aquelas mais observadas foram: as crostas hemáticas e melicéricas (100\%), as pústulas $(53,3 \%$ ) e a alopecia $(40 \%)$, sendo que as lesões tiveram início, com maior freqüência, em pavilhões auriculares $(73,3 \%)$, região ventral $(70 \%)$, ponte nasal $(53,3 \%)$ e região dorsal $(53,3 \%)$. Segundo (Ihrke et al., 1985), crostas melicéricas, escamas e alopecia, são observadas em $100 \%$ dos animais e as lesões iniciais são muito mais observadas na ponte nasal $(51,2 \%)$.

A medicação eletiva na terapia do PF é sempre a base de glicocorticóides, que são drogas relativamente seguras, desde que o paciente seja cuidadosamente monitorado durante o tratamento. Além disso, têm um baixo custo o que, normalmente, os tornam acessíveis para o proprietário. Dá-se preferência àqueles que podem ser administrados pela via oral, procurando-se evitar os chamados glicocorticóides "de depósito" ou "de longa duração", pois caso haja necessidade de se suspender a ministração da droga em função de efeitos colaterais, indesejáveis, aquelas administradas pela via oral são eliminadas muito mais rapidamente pelo organismo.

Havendo o estabelecimento do cabal diagnóstico de PF refratário à terapia ortodoxa, faz-se necessária a associação de um citostático à corticoideterapia por, aproximadamente, três semanas, para posterior reavaliação clínica e estabelecimento de doses, na freqüência adequada, de ambas as drogas, visando-se utilizar doses que tragam mínimos efeitos colaterais, mantendo o animal em boas condições clínicas e sem lesões cutâneas. No caso dos cães, em geral, opta-se pela associação da azatioprina (Beale, 1988; Scott et al, 2001; White, 2000;), nas doses e freqüências já mencionadas. Através da descrição do tempo de remissão das lesões, para os três casos, já concluídos, que se mostraram refratários à terapia apenas com prednisona, nos quais foi necessária a associação da azatioprina, notou-se que se requer um período mínimo de, pelo menos, quatro semanas para que se possa avaliar a resposta à azatioprina. Essa observação é comparável aos relatos de literatura (Beale, 1988; Scott et al., 2001; White, 2000), que citaram um período de três a seis semanas para observação de alguma melhora clínica.

Através desse levantamento, observou-se que cinco cães $(16,6 \%)$ dos 30 animais arrolados, não responderam ao tratamento à base somente de glicocorticóides. Esta observação difere das relatadas em literatura. Scott et al., 2001, afirmaram que os glicocorticóides são ineficazes em pelo menos $50 \%$ dos casos. Já Ihrke et al. (1985), 16 anos atrás, referiram que apenas $39 \%$ dos cães com PF respondem à corticoterapia. White (2000) considerou que não mais de $20 \%$ dos cães e gatos com doenças auto-imunes são bem controlados com administração apenas de glicocorticóides.

\section{Conclusões}

Com relação à casuística de animais acometidos por PF e atendidos no Serviço de Dermatologia do HOVET da FMVZI USP, pôde-se concluir que:

- apenas $16,6 \%$ dos cães não responderam à corticoterapia empregada isoladamente.

- a terapia associada (prednisona e azatioprina) é eficaz e segura para os espécimes caninos. 
- se faz necessário um período mínimo de quatro semanas para que os resultados do tratamento associado prednisonaazatioprina sejam avaliados.

- há uma aparente predisposição ao PF dos cães com raça definida, sendo as raças acometidas com maior freqüência: Cocker Spaniel e Pastor Alemão.
- há uma maior incidência do PF nos animais entre quatro e nove anos de idade.

- as lesões cutâneas elementares observadas amiúde foram: crostas hemo-melicéricas, pústulas por sobre as áreas de alopecia.

- as lesões iniciais se localizaram, principalmente, em paviIhões auriculares, região ventral e ponte nasal.

\section{Agradecimentos}

Aos médicos-veterinários Ana Luíza Basso Penteado, Cibele Rossi Nahas e Ronaldo Lucas que militaram no Serviço de Dermatologia do HOVET/USP durante o período de 1986 a 1995, e que foram responsáveis por parte dos diagnósticos de pênfigo foliáceo estabelecidos.

\section{Referências}

BEALE, K.M. Azathioprine for treatment of immune-mediated diseases of dogs and cats. J. Am. Vet. Med. Assoc., v. 192, n. 9, p. 1316-1318, 1988.

BENSIGNOR, E.; PIN, D.; CARLOTTI, D.N. Le Pemphigus Foliacé des carnivores domestiques. Ann. Méd. Vét., v. 142, p. 5-13, 1998.

HALLIWELL, R.E.W.; GOLDSCHMIDT, M.H., 1977 apud SCOTT, D.W.; LEWIS, M.R., 1981, p. 148.

IHRKE, P.J.; STANNARD, A.A.; ARDANS, A.A.; GRIFFIN, C.E. Pemphigus foliaceus in dogs: A review of 37 cases. J. Am. Vet. Med. Assoc., v. 186, n. 1, p. 59-66, 1985

NASCIMENTO, M.C.M.O.; LAHM, M.J.C.; FRANCO, S.R.V.S. Pênfigo foliáceo - relato de um caso não responsivo à corticoterapia em um cão. R. bras. Ci. Vet., v. 7, supl., 2000.
SAMPAIO, S.A.P.; RIVITTI, E.A. Pênfigo foliáceo. In: SAMPAIO, S.A.P.; RIVITTI, E.A. Dermatologia, 2. ed., p. 231-238, 1998.

SCOTT, D.W.; LEWIS, M.R. Pemphigus and pemphigoid in dog and man: Comparative aspects. Am. Acad. Derm., v. 5, n. 2, p. 148-167, 1981. SCOTT, D.W.; MILLER JR, W.H.; GRIFFIN, G.E. Immune-mediated disorders. In: SCOTT, D.W.; MILLER JR, W.H. e GRIFFIN, G.E. Small Animal Dermatology. $6^{\text {th }}$ ed. Philadelphia: WB Saunders Company, 2001. WERNER, A.H. Recognizing and treating discoid lupus erythematous and pemphigus foliaceus in dog. Comp. An. Pract., p. 955-966, 1999. WHITE, S.D. Nonsteroidal Immunosupressive Therapy. In: BONAGURA, J.D. Kirk's Current Veterinary Therapy, 13. ed., 2000, p. 536-538.

WHITE, S.D. Treatment of Autoimmune Skin Disease. In: 4 World Congress of Veterinary Dermatology, San Francisco, California, August 30-September 2, 2000, p. 173-174. 